\title{
TREE-RING GROWTH AND WOOD CHEMISTRY RESPONSE TO MANIPULATED PRECIPITATION VARIATION FOR TWO TEMPERATE QUERCUS SPECIES
}

\author{
REBEKAH J. WAGNER ${ }^{1 *}$, MARGOT W. KAYE ${ }^{1}$, MARC D. ABRAMS ${ }^{1}$, PAUL J. HANSON ${ }^{2}$, and \\ MADHAVI MARTIN ${ }^{2}$ \\ ${ }^{1}$ School of Forest Resources, Forest Resources Building, The Pennsylvania State University, University Park, PA, \\ 16802, USA \\ ${ }^{2}$ Environmental Sciences Division, Oak Ridge National Laboratory, P.O. Box 2008, Oak Ridge, TN, 37831, USA
}

\begin{abstract}
We examined the relationship among ambient and manipulated precipitation, wood chemistry, and their relationship with radial growth for two oak species in eastern Tennessee. The study took place on the Walker Branch Throughfall Displacement Experiment (TDE) site, located at the Oak Ridge National Laboratory in Oak Ridge, TN. Two dominant species, white oak (Quercus alba) and chestnut oak (Quercus prinus), were selected for study from a 13-year experiment of whole-stand precipitation manipulation (wet, ambient and dry). The relationships between tree-ring width and climate were compared for both species to determine the impact of precipitation manipulations on ring width index. This study used experimental spectroscopy techniques to measure the sensitivity of treering responses to directional changes in precipitation over 13 years, and the results suggest that oaks at this study site are resilient to imposed changes, but sensitive to inter-annual variations in climate. Laser-induced breakdown spectroscopy (LIBS) allowed us to measure nutrient intensities (similar to element concentrations) at $0.5-1.0 \mathrm{~mm}$ spacing along the radial growth axis of trees growing in the wet, ambient, and dry treatment sites. A difference in stemwood nutrient levels was observed between the two oak species and among the three treatments. Significant variation in element intensity was observed across treatments for some elements ( $\mathrm{Ca}, \mathrm{K}, \mathrm{Mg}, \mathrm{Na}, \mathrm{N}$ and $\mathrm{P}$ ) suggesting the potential for long-term impacts on growth under a changing climate regimes for southeastern oaks.
\end{abstract}

Keywords: dendroecology, global change, LIBS, nutrients, oak, Quercus.

\section{INTRODUCTION}

The Intergovernmental Panel on Climate Change (IPCC) reported that the world's climate has changed significantly over the last century, and that anthropogenic forcing is a contributing factor (Solomon et al. 2007). A major concern of changing climatic conditions is the potential alterations of precipitation regimes worldwide and the impact they may have on forest ecosystems (Hanson and Weltzin 2000; Johnson et al. 2000). Global circulation models predict that increasing concentrations of atmospheric $\mathrm{CO}_{2}$ and other greenhouse gases will increase the frequency and severity of

*Corresponding author: rjw253@psu.edu droughts in regions currently occupied by temperate forests (Pastor and Post 1988; Neilson et al. 1989; Weltzin et al. 2003; Ciais et al. 2005; Fay et al. 2008; Piovesan et al. 2008).

In the southeastern United States, increasing temperatures combined with decreasing levels of precipitation are predicted to alter tree growth and distribution across the landscape (Wullschleger and Hanson 2003). Trends over the last 100 years have shown an increase in cool-season precipitation coupled with increasing occurrence and intensity of warm-season drought (Senior et al. 2002). With predicted changes in precipitation patterns and the possibility of more frequent and intense droughts, southeastern forests could potentially be at risk for higher mortality associated 
with water stress (Wullschleger and Hanson 2003). Increased drought frequency in the Southeast that overlaps with periods of active stem growth is expected to reduce the annual ring growth of most upland tree species (Hanson et al. 2001; Hanson et al. 2003).

Radial growth can be limited by physiological processes limited by unfavorable climatic conditions (Ericsson et al. 1996). At the tree-ring level, trees growing on favorable sites may exhibit complacent tree-ring growth patterns, with little sensitivity to climate variation (Kubiske and Abrams 1994). In this study, we focus on two widely distributed eastern species, white oak (Quercus alba L.) and chestnut oak (Quercus prinus L.), both of which are considered to be drought resistant with physiological and morphological adaptations that allow them to persist on moisture-limited sites. The broad distribution of these species, coupled with morphological and physiological adaptation to drought, makes them ideal for developing a better understanding of eastern forest ecosystems under future climate change scenarios.

Dendrochemical analysis can be used to recognize temporal trends in wood composition that may be related to physiological processes and environmental conditions such as moisture regimes (St. George et al. 2006). The primary assumption of dendrochemical studies is that the chemical makeup of the annual rings at least partially reflects the chemistry of the environment in which it was formed (Amato 1988). The major confounding factor in dendrochemical analysis is the potential radial translocation of elements across ring boundaries, which is based on the mobility of the elements within the xylem. Most critical nutrients required for radial growth $(\mathrm{Ca}$, $\mathrm{K}, \mathrm{Mg}, \mathrm{Na}, \mathrm{N}$ and $\mathrm{P}$ ) are mobile within the xylem, but can still be used to identify patterns of tree responses to environmental conditions over time (Cutter and Guyette 1993). Mineral element concentrations across rings within an individual may be variable, but similarities in the patterns of variation of elemental concentrations in two species might indicate a common environmental or physiological influence (Penninckx et al. 2001).

In this study, we analyzed the impact of precipitation on wood chemistry and radial growth for two oak species in eastern Tennessee. Two dominant species Quercus alba L. (white oak) and Quercus prinus L. (chestnut oak) were selected for study within a 13-year experiment on wholestand manipulation of precipitation at three levels (wet, ambient and dry) (Hanson et al. 1995, 1998).

A primary goal of this study was to evaluate the impacts of persistent increased and decreased levels of precipitation on two common eastern oak species (Wullschleger and Hanson 2003). Tree-ring samples collected after the final year of the project were used to reconstruct radial growth and wood chemistry responses to experimentally altered precipitation for two species in a southern mixed oak forest community. In this paper we ask two broad questions. First, are imposed precipitation treatments reflected in the annual radial growth of mature oak trees? Second, can spectroscopic analysis detect treatment effects in the elemental analysis of stemwood tissue? Although previous research on the Throughfall Displacement Experiment (TDE) site has shown no response in the basal area growth in the early years of the experiment (Hanson et al. 2001), we expected that annual ring growth over the 13-year period of the study would reflect precipitation manipulations, with increased tree-ring widths on the wet treatments and decreased on the dry treatments. We also expected that the mineral nutrient levels in the ambient treatment trees would exceed that of trees sampled on either the wet and dry treatment sites as a result of soil nutrient immobilization in dry treatments and leaching in wet treatments. Mineral nutrient intensity levels serve as a proxy for elemental concentrations based on the measured wavelengths emitted during spectroscopic analysis. We expected little variation in the nutrient intensity levels between the two oak species based on their similar physiological tolerance to water stress.

\section{METHODS}

The study samples were collected from the Walker Branch Throughfall Displacement Experiment site, located at the Oak Ridge National Laboratory in Oak Ridge, TN. This site is located on the Walker Branch Watershed $\left(38^{\circ} 58^{\prime} \mathrm{N}\right.$ and 
$\left.84^{\circ} 17^{\prime} \mathrm{W}\right)$. The long-term mean annual precipitation is $1,352 \mathrm{~mm}$ and mean temperature is $14.2^{\circ} \mathrm{C}$ (Hanson et al. 2001). Soils are acidic in nature (pH 3.5 to 4.6) and classified as Typic Paleudults, formed from infertile silt loams that are permeable with a mineral bedrock depth of $30 \mathrm{~m}$. The study site contains a mixture of hardwood species with white oak and chestnut oak dominating the upper canopy. Species are similarly distributed across the three treatments. The site was selected initially for its fairly uniform slope and consistent soils, as well as a land-use history of logging, farming and grazing, which is consistent with the surrounding area.

As a part of the 13-year study, throughfall precipitation on three $6,400 \mathrm{~m}^{2}$ plots was manipulated to produce wet $(c a .+33 \%)$, dry $(c a .-33 \%)$ and ambient water treatments within the study area. To achieve the precipitation manipulation treatment goals, troughs were installed beneath the canopy of the "dry" treatment plot to capture and divert passing precipitation or throughfall. The collected throughfall precipitation was passively transported across the ambient treatment and then applied to the "wet" treatment plot through a PVC drip irrigation system. All trees within the treatment plots were tagged and monitored for morphology, physiology and nutrient cycling studies that were carried out over the 13-year study period.

For our analysis of tree rings and precipitation, we used a 25 -year precipitation record from 1981-2005, providing 12 years of pre-treatment data from 1981 to 1992 , and 13 years of data spanning the period of manipulation from 1993 to 2005. The pre-treatment records for regional precipitation and temperature data were obtained from the National Oceanic and Atmospheric Administration (NOAA) in Oak Ridge, Tennessee, and the long-term record for Walker Branch Watershed located on the Oak Ridge Reservations (http://walkerbranch.ornl.gov/). Data from 1993 to 2005 were obtained from measurements taken at the specific TDE study site on Walker Branch Watershed. A comparison of the NOAA data from 1993-2005 was made to the TDE site data for monthly temperature and precipitation values. A regression analysis of the temperature and
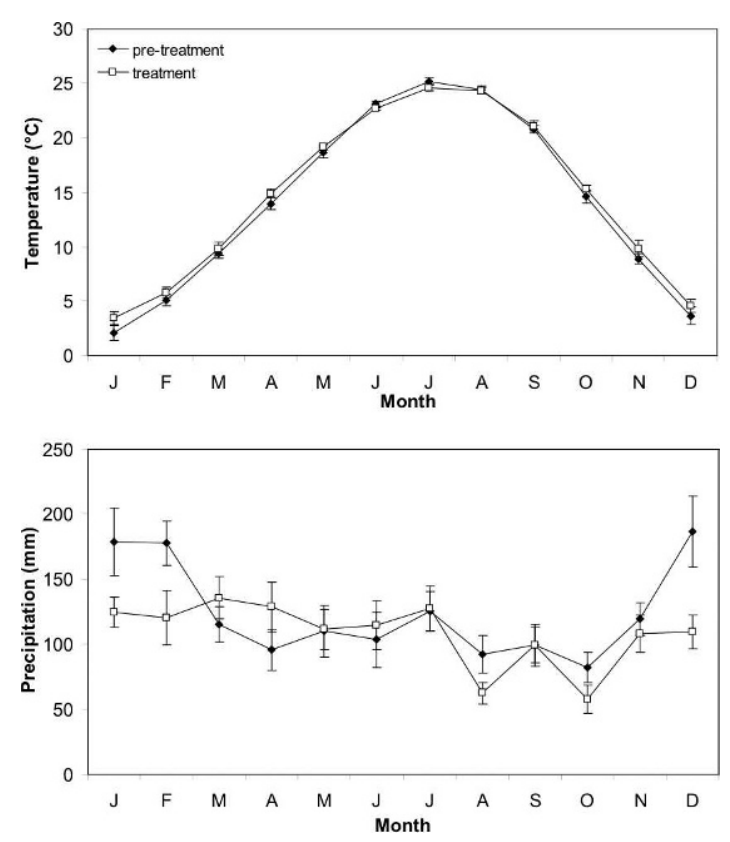

Figure 1. Comparisons of average monthly pre-treatment (1981-1992) temperature and precipitation and treatment (1993-2005) temperature and precipitation. Standard error is denoted by bars.

precipitation found that the values recorded by NOAA and the TDE site are highly correlated $\left(\mathrm{R}^{2}\right.$ $=0.99$ temperature and $\mathrm{R}^{2}=0.81$ precipitation, data not shown), which demonstrates a constancy in the climatic data used in these analyses. Within the study period, the TDE site experienced five drought years (1993, 1995, 1998, 2001, and 2005) that were identified using soil-water potential as the primary measurement of soil water status, determined to be a key variable for developing relationships between plant responses and available precipitation (Wullschleger and Hanson 2003). Pre-treatment (1981-1992) and treatment (1993-2005) temperature were not different (Figure 1). Average monthly precipitation records showed higher winter precipitation in the pretreatment than the treatment periods (Figure 1). Detailed site descriptions and experimental design are described in Hanson et al. (1995, 1998).

Tree cores collected in 2005 were used to determine the relationship among radial growth, wood chemistry, and manipulated precipitation of species sampled within the treatments of the TDE. Twelve dominant trees of two oak species (white 
oak and chestnut oak) were selected from each of the three treatment plots (wet, dry and ambient) and cored at breast height. This provided us with 12 cores of each species per treatment combination. All increment cores $(\mathrm{n}=72)$ from the study area were dried, mounted, and sanded. Cores were visibly crossdated and measured for annual radial growth to the nearest $0.002 \mathrm{~mm}$ with the UniSlide "TA" Tree-Ring Measurement System (Velmex Inc. Bloomfield, N.Y.). Crossdating accuracy was verified using the program COFECHA in the International Tree-Ring Data Bank Program Library (ITRDBL) Version 2.1 (Cook and Holmes 1997).

Raw ring-width measurements were standardized for each core by subtracting the mean ring width for the period 1981-2005 from the ring width of each year. This 25-year period encompasses 12 years of pre-treatment data and 13 years of treatment data. We chose this standardization method because the 25 years of raw ring width data were from the outermost section of mature second-growth oak stems, did not show an agerelated decline in tree-ring width, and therefore did not need to be detrended. The standardized ring-width data from the 12 cores from a species within a treatment were averaged to create a ringwidth index (RWI) for each of the two species from the three treatments. Each of these six RWI was divided into two sections, a pre-treatment index from 1981-1992 and a treatment index from 1993-2005. Simple correlations between monthly precipitation and temperature and annual RWI were calculated (PRECON 5.17C) for the previous October to November of the current year to account for any lag in climatic influence because it has been shown that the previous winter's climate can have strong correlations to the next year's ring growth occurring from April to October (Fritts 2001). Regression analysis was preformed using the RWI for each species/treatment combination and mean annual precipitation from 1981-2005. Statistical analyses were considered significant at $\alpha$ $=0.05$.

Laser-induced breakdown spectroscopy (LIBS) was performed to reconstruct annual nutrient concentrations of the two study species. LIBS analysis was performed on 36 oak cores (6 cores per species per treatment) because of the time-intensive nature of the analysis. The average diameter of a sample point was $2.4 \mu \mathrm{m}$ with a standard deviation of $1.5 \mu \mathrm{m}$. Each core was sampled at a regular interval of 0.5 or $1.0 \mathrm{~mm}$ for the rings from 1981-2005 of the tree core. Average ring widths for chestnut oak were $2.76 \pm 0.44 \mathrm{~mm}$ and white oak were $2.25 \pm 0.24 \mathrm{~mm}$ and 40 to 150 points were sampled on each core depending on the length. The advantage of this technique is that LIBS is done under atmospheric conditions without a vacuum and minimal sample preparation. This technique has a pulsed laser as the excitation source that forms a plasma when a laser beam of sufficient energy is focused onto a small volume $\left(\sim 14 \times 10^{-9} \mathrm{~cm}^{3}\right)$, creating a power density inside the volume exceeding tens of gigawatts per square centimeter. The core sample is vaporized in the focal volume into its elemental constituents. LIBS is typically a surface analytical technique, with each laser pulse vaporizing a microgram or submicrogram sample mass. However, the rapidity of sampling (typically $10 \mathrm{~Hz}$ laser repetition rate) and ability to scan a sample surface, ablate a hole into a solid sample with repeated laser pulses for depth profiling, or focus the laser spark below the surface of a liquid sample permits more versatile analyses and provides sufficient statistics for bulk sampling (Martin and Cheng 2000). All elements have emission lines within the $1,100 \mathrm{~nm}$ to $170 \mathrm{~nm}$ wavelength range (Martin et al. 2003).

The plasma produced at each sample point was analyzed to calculate the intensity (unitless), or level of concentration, of each elemental constituent with a known wavelength value. The known wavelength values $(\mathrm{nm})$ for six nutrient variables $(\mathrm{Ca}, \mathrm{K}, \mathrm{Mg}, \mathrm{Na}, \mathrm{N}$ and $\mathrm{P}$ ) were identified as follows: Ca: 393, 396, 422, 445.38, 612.18, 616.18, 643.78; K: 496.64, 508.56, 578.40; Mg: 496.62, 516.42, 654.66; Na: 589.16, 589.76; N: 496.54, 500.6, 568.1, 744.4, 747.5; and P: 253.48, $253.64,255.4,620.08$. The measured intensities for all wavelengths were averaged for each nutrient to assess the total intensity for each of the six nutrients in every sample point. Spectroscopic sample points that fell within a single growth ring were averaged to calculate an annual intensity of 
each mineral, combining LIBS readings within each growth ring and incorporating both early and late wood measurements.

Multivariate analysis of variance (MANOVA) tested for differences in wood nutrient levels among treatments and species. A MANOVA model was selected to test multiple dependent variables, while controlling for the correlation between them, allowing us to determine the effects of the experimental treatments. Univariate and bivariate normality assumptions were tested graphically and shown to have normal distributions before fitting the MANOVA model that was reduced to only significant factors in the final model. The resulting model included year, species, treatment and the interaction between treatment and species. The least square means output from the final MANOVA model were used to construct 95\% Bonferroni Confidence Intervals to make inferences on the interactions for nutrients, treatment and species.

\section{RESULTS}

Radial growth of the two study species at Oak Ridge was correlated to annual precipitation but not affected by throughfall displacement during the 13-year treatment period. White oak showed low ring-width inter-series correlation coefficients in all three treatments (ambient $r=$ 0.303 , wet $r=0.091$, dry $r=0.293$ ), whereas chestnut oak had higher values in all treatments (ambient $r=0.416$, wet $r=0.311$, dry $r=0.505$ ). All samples showed similar mean sensitivities (white oak ambient $\mathrm{ms}=0.253$, wet $\mathrm{ms}=0.260$, dry $\mathrm{ms}=0.249$; chestnut oak ambient $\mathrm{ms}=0.226$, wet $\mathrm{ms}=0.243$, dry $\mathrm{ms}=0.204)$. All 12 species and treatment combinations were found to have a significant positive correlation between ring-width indices and mean annual precipitation, but very little variance in radial growth is explained by precipitation (white oak, ambient $\mathrm{R}^{2}=0.02$, wet $\mathrm{R}^{2}=0.03$ dry $\mathrm{R}^{2}=0.05$; for chestnut oak, ambient $\mathrm{R}^{2}=0.014$, wet $\mathrm{R}^{2}=0.029$, dry $\mathrm{R}^{2}=$ 0.025 ) (Figures 2 and 3). No difference was found between the pretreatment and treatment RWI for any species-treatment combination, with the exception of chestnut oaks sampled from the wet treatment plot $(\mathrm{p}=0.03)$ (Supplementary Material Table 1). Correlations among chestnut or white oak RWI, average monthly precipitation, and temperature showed no consistent response to any of the imposed precipitation treatments. However, there were strong responses to monthly variation in temperature and precipitation over the pre-treatment and treatment periods (Figures 4 and 5). The greatest difference was observed during the pretreatment period (19811992), when average monthly winter precipitation was significantly higher than during the treatments period (1993-2005) (Figure 1), and this was observed in the strong positive correlation between precipitation and RWI in DecemberFebruary during the pretreatment period. During the treatment period, chestnut oak RWI showed a negative correlation to winter precipitation during the same months. Chestnut oak had a significant negative correlation to late summer (AugustOctober) precipitation during the treatment period that was not seen in the previous 12 years (Figures 4 and 5).

The intensity levels of six critical nutrients in the stemwood of mature chestnut and white oaks grown under manipulated precipitation treatments for 13 years showed that white oak had significantly higher intensity level for $\mathrm{Ca}, \mathrm{N}$ and $\mathrm{Na}$ when compared to chestnut oak samples. However, for the remaining three nutrients, $\mathrm{K}, \mathrm{Mg}$ and $\mathrm{P}$, we found no significant difference in intensity levels between the two oak species (Figure 6). When we examined treatment-specific responses of each nutrient for both white and chestnut oak, we found that there was no consistent pattern of nutrient intensities across the three treatments. Potassium (K) and $\mathrm{Na}$ showed no significant difference in intensity levels between the wet and ambient treatments, however the dry treatment had significantly lower intensities of both nutrients, when compared to the ambient treatment. Both $\mathrm{N}$ and $\mathrm{Mg}$ were found at lower intensity levels on the dry treatment, but there was no significant difference measured between the wet and ambient treatments. Only $\mathrm{Ca}$ and $\mathrm{P}$ were not found to have significant differences in nutrient intensities across the three treatment plots (Figure 7). 

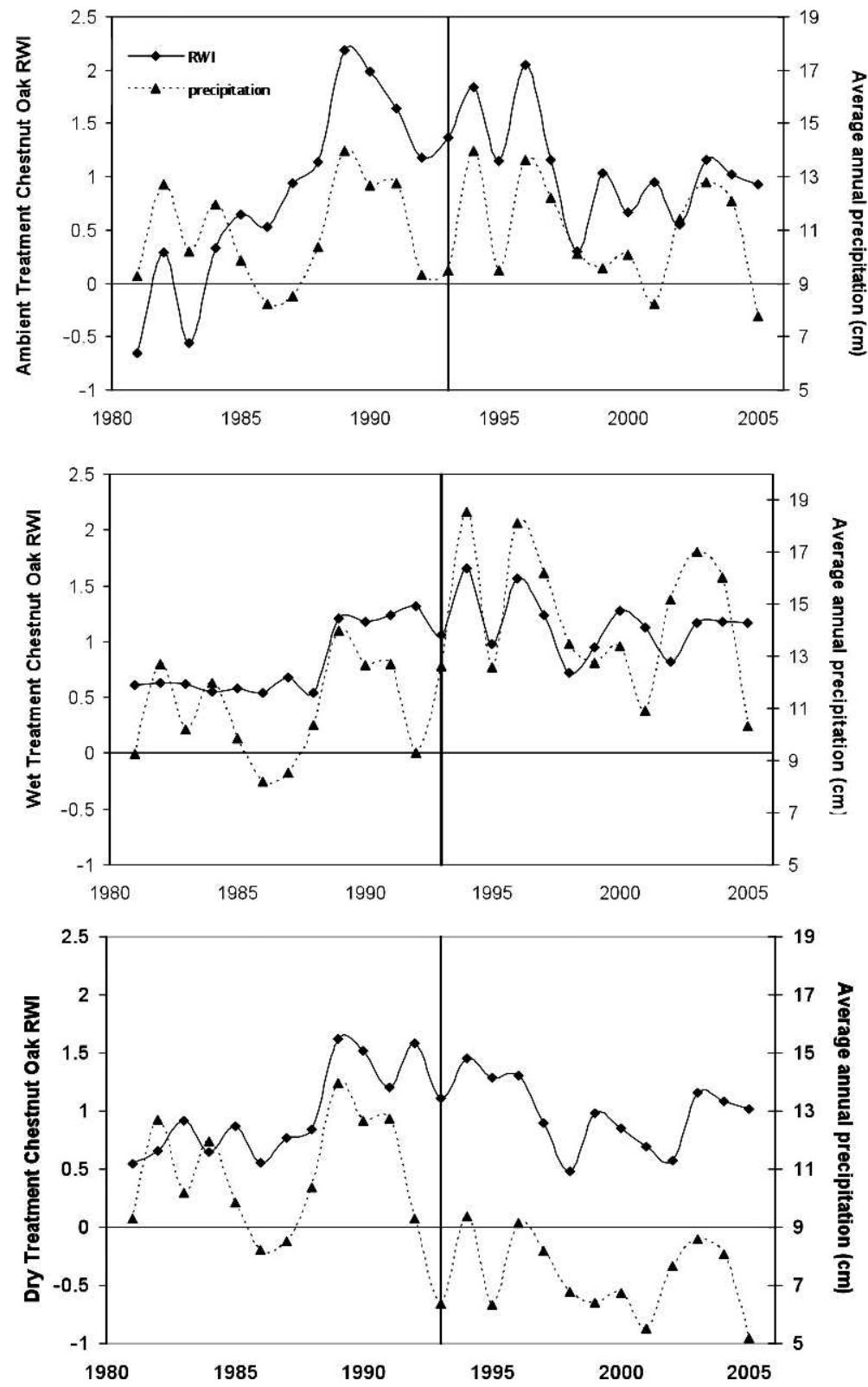

Figure 2. Ring width indices (RWI) for chestnut oak species grown on three treatments (ambient, wet and dry) compared against the mean annual precipitation values within each treatment. Vertical line indicates the year in which the treatment regime began (1993).

\section{DISCUSSION}

We expected 13 years of altered precipitation to affect the annual ring growth of two dominant oak species in the southeastern US; however neither species was sensitive to a $\sim 30 \%$ increase or decrease in throughfall. We found interannual responses to seasonal precipitation and temperature and the inherent variation in growth between species to be the most significant variables influencing observed patterns in annual ring growth. On the Throughfall Displacement Exper- 

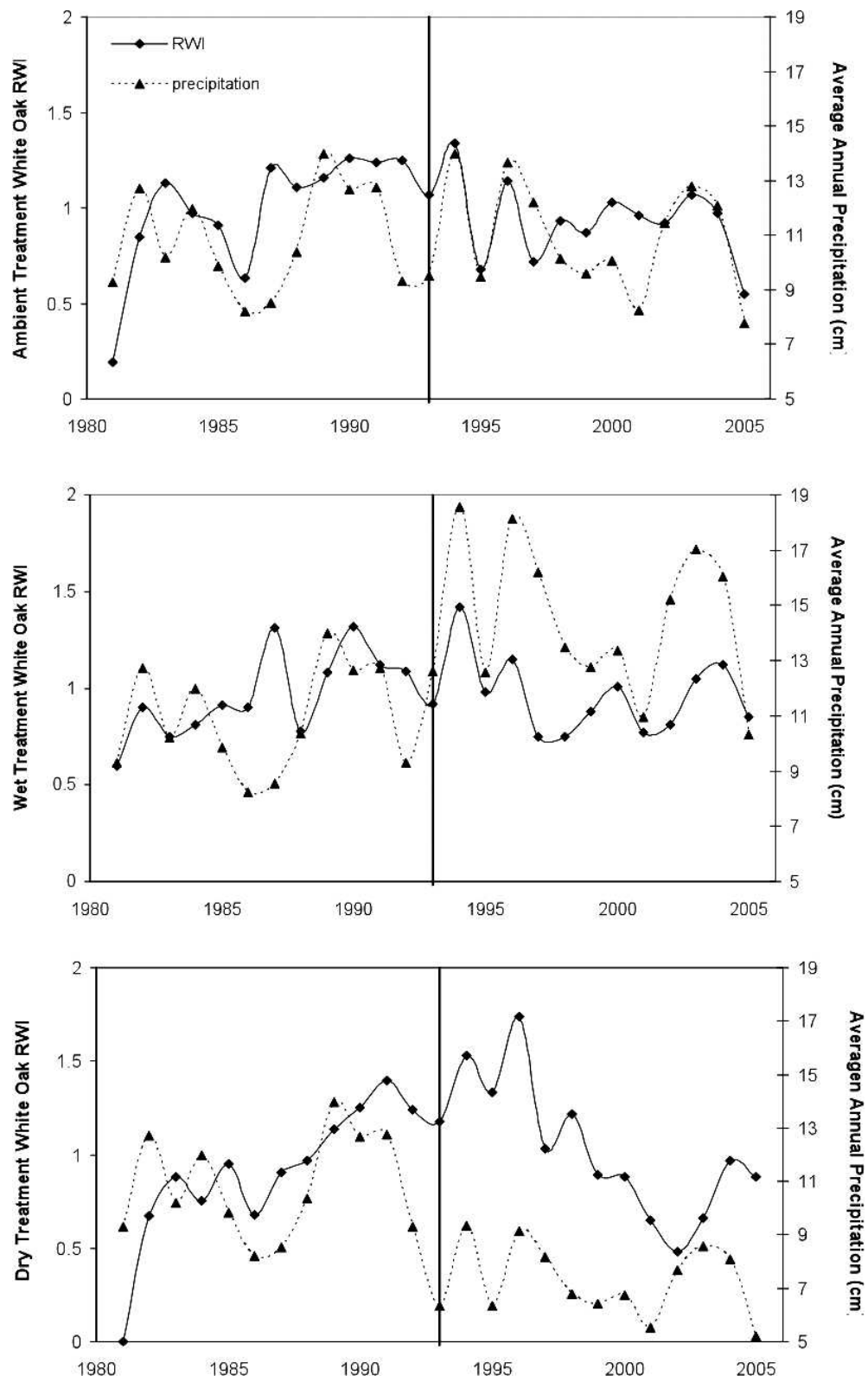

Figure 3. Ring width indices (RWI) for white oak species grown on three treatments (ambient, wet and dry) compared against the mean annual precipitation values within each treatment. Vertical line indicates the year in which the treatment regime began (1993).

iment site, white and chestnut oak maintained average radial growth measurements greater than $2 \mathrm{~mm}$ per year, even in years of significant drought when ring growth is most likely to be depressed. Comparisons between RWI and average monthly precipitation differed between the pretreatment and treatment period (Figures 2 and 3). However, growth of the sampled oaks showed more sensitivity to annual variation in precipitation than to the 13-year imposed treatment regime. In addition, both chestnut and white oak showed a greater response in radial growth to seasonal variations in precipitation and temperature (Figures 4 and 5) than the imposed precipitation 

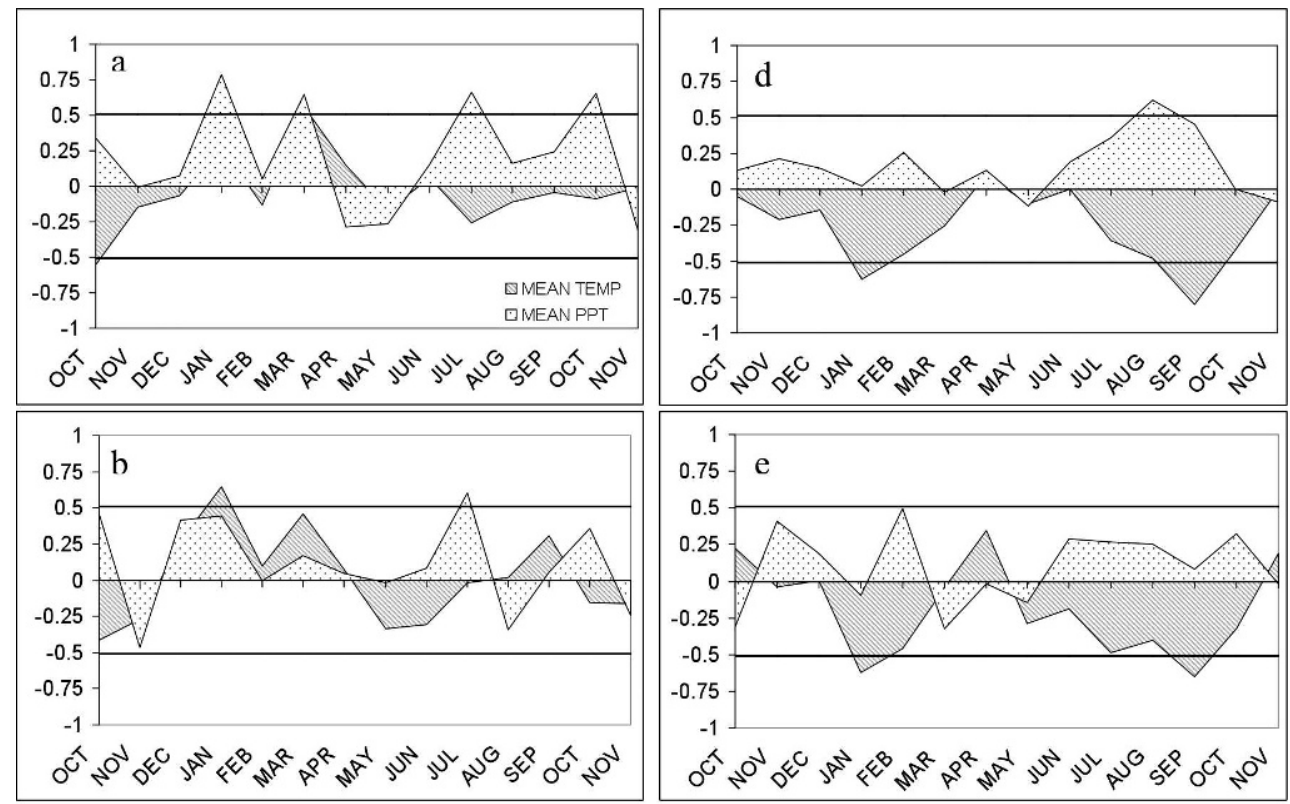

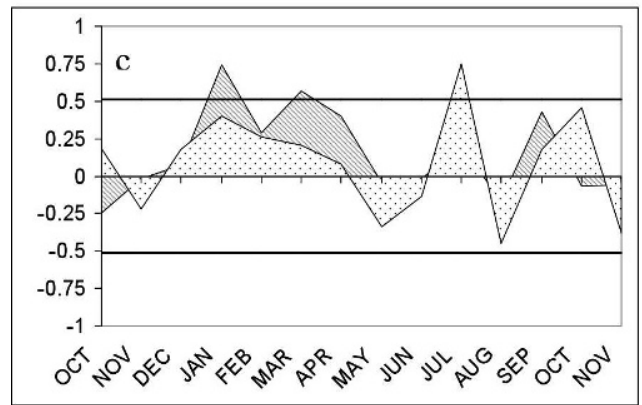

Month

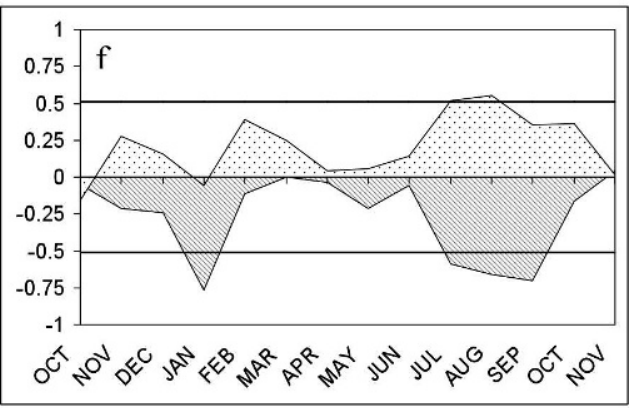

Month

Figure 4. Comparisons of correlation coefficients between RWI, monthly precipitation and temperature for pre-treatment years (1981-1992, left graphs) and treatment years (1993-2005, right graphs) for chestnut oak on the designated ambient (a, d), dry (b, e), and wet $(\mathrm{c}, \mathrm{f})$ treatment plots. All points occurring above 0.25 or below -0.25 are considered to be significant correlations.

manipulation regime of the TDE study site. We found that there was a sign reversal of the correlation value between RWI and average monthly winter temperatures for chestnut oaks grown on all three treatment conditions. One potential explanation is that natural drought events occurred during the 13-treatment period that were not reflected in the monthly average precipitation record. A similar reduction in treering width was observed in white spruce as a result of temperature-induced drought stress and the correlation coefficient values showed a similar change from positive to negative (Barber et al. 2000; D'Arrigo et al. 2004). At the stand-level, tree-ring growth of both species responded strongly to the annual ambient conditions regardless of the implemented precipitation treatment being received. Hanson et al. (2001) found that from 1993-1999 the implemented treatments on the TDE site had no affect on the basal area growth of the large trees, but that the overall growth was two to three times greater in wet years relative to dry years.

The TDE treatments have been shown to influence forest physiological processes (Grebe et al. 1998; Tschaplinski et al. 1998; Wullschleger et al. 1998), although Hanson et al. (2001) found no strong relationship between variation in growing 

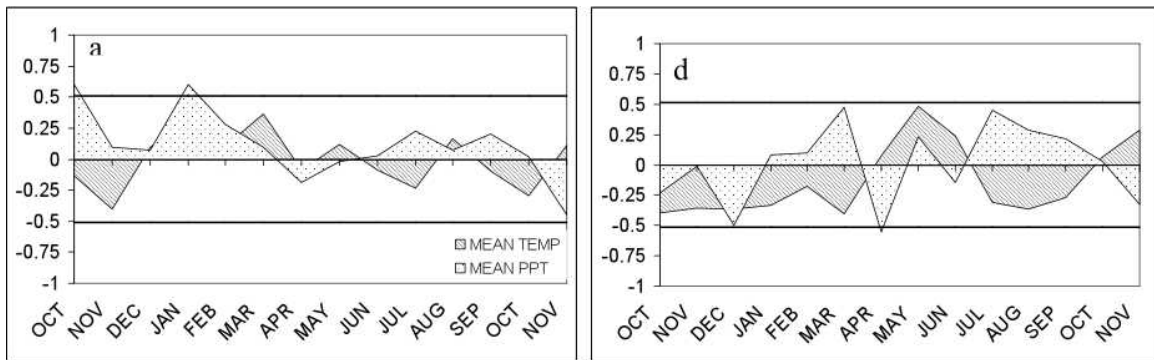

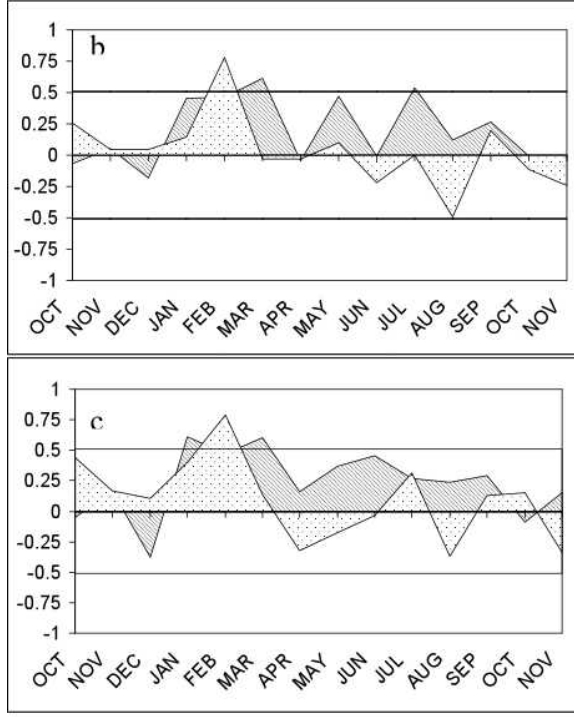

Month

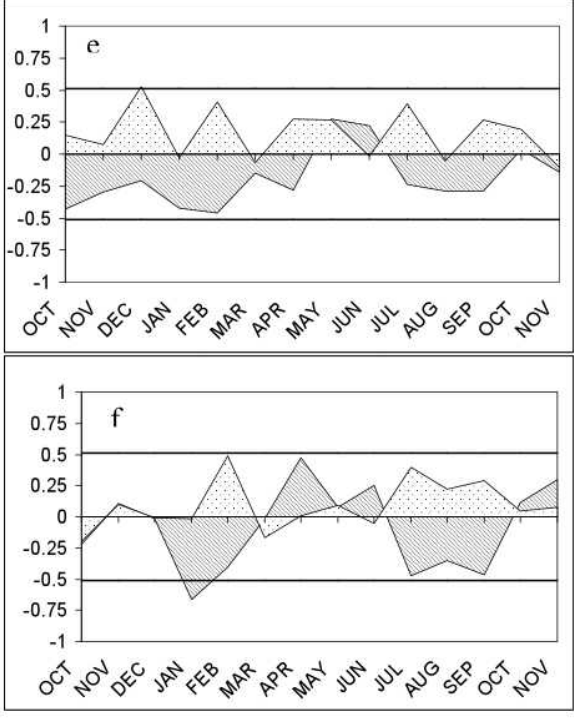

Month

Figure 5. Comparisons of correlation coefficients between RWI, monthly precipitation and temperature for pre-treatment years (1981-1992, left graphs) and treatment years (1993-2005, right graphs) for white oak on the designated ambient (a, d), dry (b, e), and wet (c, f) treatment plots. All points occurring above 0.25 or below -0.25 are considered to be significant correlations.

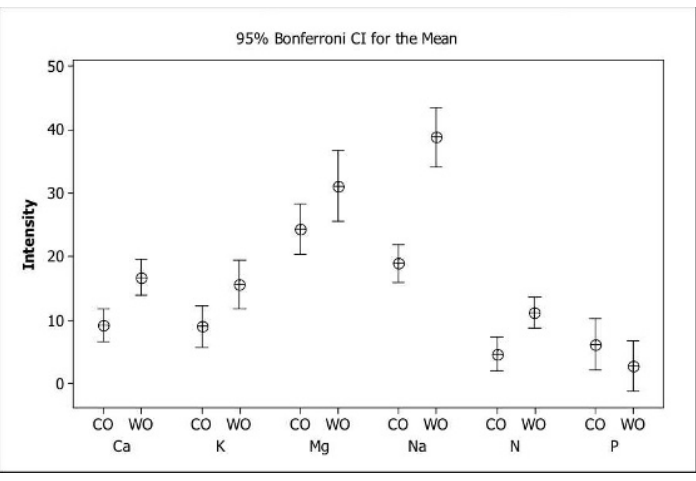

Figure 6. Comparison of the $95 \%$ Bonferroni confidence intervals for chestnut (CO) and white oak (WO) RWI to determine significant variation among six sampled nutrients.

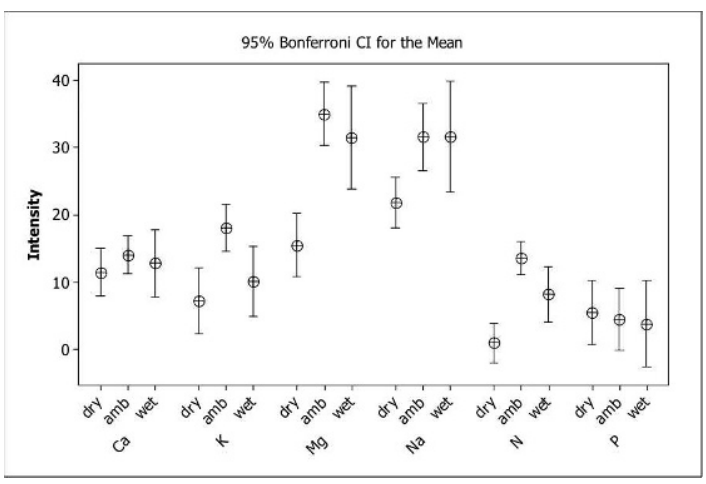

Figure 7. Comparison of the $95 \%$ Bonferroni confidence intervals for RWI of both chestnut and white oak under three imposed precipitation treatments (dry, ambient and wet) to determine significant variation among six sampled nutrients. 
season precipitation and annual basal area growth of large trees based on dendrometer band data. This discrepancy was explained on the basis of the timing of basal area growth (early spring) of species on the TDE site and the major drought periods that occurred in the late summer months (Hanson et al. 2001). When monthly precipitation and temperature correlations were averaged across treatments, white oak did not record the strongest response when compared to chestnut oak, and its higher mean sensitivity $(0.229$ and 0.254 , respectively) may indicate that a stronger response to precipitation and temperature may be masked by other biotic or abiotic factors. In contrast, we found that chestnut oak had higher inter-series correlation and lower climate correlation than white oak ( 0.411 and 0.224 , respectively). These data may indicate that the mature oaks at the TDE study site were able to cope with experimental changes in available surface moisture, allowing for sustained growth in periods of induced drought. Hanson et al. (2001, 2003) attributed this lack of radial growth response to deep root access to water supplies during periods of surface drying. As expected, the RWI and precipitation correlations show the same response over the 25year period of this study, further supporting the hypothesis that seasonal timing of rainfall will have a greater impact on mature tree growth than the sustained and constant changes in the annual percentage of precipitation received over the entire year. Given the broad geographical distribution of both the eastern oak species, the resilience to the 13-year manipulated drought conditions at the TDE site was unexpected. However the limited response of the pretreatment and treatment period indicated that the manipulated levels of precipitation at the TDE site did not cross the droughtstress threshold required to be reflected in the tree rings of the two study species.

Although the stem growth of the mature oaks on the TDE site changed with the seasonal timing of rainfall, little is known about nutrient concentrations in relation to moisture variation. Other studies have suggested that although dendrochemical studies may show high tree-to-tree variability in elemental concentrations, selected elements display both monthly and annual trends that appear to be related to internal physiological processes and external environmental forcing, such as climate (St. George et al. 2006). For this study, the problem of radial translocation is diminished because our goal was not to identify specific events, but rather patterns of elemental availability over a 13-year period in the outer rings of mature trees. However, it is important to be aware of the possibility that patterns in the elemental concentrations may be smoothed out or eliminated as a result of radial translocation. Another factor to consider with stemwood nutrient analysis is the crossing of the heartwoodsapwood boundary, which can result in drastic changes in the concentration of elemental nutrients along a tree core. Wardell and Hart (1973) found that for white oak, each element had a characteristic pattern of tissue concentration change, with $\mathrm{K}, \mathrm{Mg}, \mathrm{Ca}$, and $\mathrm{N}$ occurring in significantly higher concentrations in the sapwood and decreasing sharply across the sapwoodheartwood boundary. These sharp decreases in concentration were not observed in the core samples measured for this study, which indicates that the 13-year tree-ring series measured for the two oak species was limited to the sapwood of each core.

We expected variation in the nutrient intensity levels to reflect both the imposed precipitation treatment and the study species' physiological tolerance to water stress (Abrams 1990). Large trees, and oaks in particular, have attributes that can facilitate drought tolerance, including deep rooting systems, low relative growth rates and greater capacity for osmotic adjustment to adequately maintain physiological activity during periods of drought (Kramer 1980; Abrams 1988a, 1988b; Tschaplinski et al. 1998). Laser induced breakdown spectroscopy analysis of the stemwood showed no significant difference in the $\mathrm{Ca}$ and $\mathrm{P}$ levels across all treatments, although $\mathrm{N}$, $\mathrm{Mg}, \mathrm{K}$ and $\mathrm{Na}$ were found at significantly different intensities between the three treatments. These results are consistent with soil nutrient analysis from the 13-year study period, which found that there was no statistically significant effect of the treatments on soil $\mathrm{Ca}^{2+}$ or P (Johnson et al. 2008). However, Johnson et al. (2008) also 
found that there was no significant effect on the soil $\mathrm{N}$ or $\mathrm{Mg}^{2+}$, which were significantly lower in the stemwood of the dry treatment.

We expected that the mineral nutrient composition of the stemwood of both oak species in the ambient treatment site would exceed that of trees found on both the wet and dry treatment sites as a result of nutrient leaching and immobilization within the soil. Previous studies at the TDE site have demonstrated that there was significant immobilization of $\mathrm{N}$ on the dry treatment site as a result of decreased decomposition of the litter layer (Johnson et al. 2008). LIBS analysis showed a significantly lower intensity in the dry treatment plot (Figure 7). These results align with the expectation that increased immobilization of $\mathrm{N}$ on dry site will be observable in the lower intensities in the stemwood (Johnson et al. 2002). Of the six critical nutrients sampled in this study, only $\mathrm{P}$ did not exhibit any significant difference in intensity levels across species or treatments. The relative stability of $\mathrm{P}$ levels within all the cores sampled, regardless of treatment or species, can be related to the biological importance of the nutrient and possible limited availability within the Walker Branch Watershed, which may drive trees to resorb and reallocate this limiting nutrient (Hanson et al. 2003). Results of this study show that the LIBS analysis of the dendrochemistry of two co-occurring dominant species growing under manipulated precipitation regimes are in agreement with both foliar and soil nutrient studies done within the TDE experimental period and found that although mature trees do show some response to changes in annual precipitation, the primary driving force in this ecosystem seems to be seasonal variation in precipitation and the resilience of mature forest ecosystems.

\section{CONCLUSION}

Modern climate and tree-ring relationships are the basis for climate reconstructions spanning the last 1,000 years or more. This analysis of tree radial growth before and during a 13-year precipitation manipulation documented a greater resilience of mature deciduous temperate forests to decadal altered precipitation than had been expected (Wullschleger and Hanson 2003). This study shows that spectroscopic analysis of stemwood can highlight differential responses to the effects of the imposed precipitation treatments on species growing under manipulated conditions.

The impact of changing climate on the development of the mixed oak forests of the Southeastern United States is largely unknown. Although the results of this study imply a possible resilience of oak trees to climate stressors, the trees sampled for the study were growing at a relatively favorable site, leaving the possibility that these results may not hold true for sensitive species growing on more stressed locations. The lack of sensitivity of radial tree growth to manipulated climate in this study draws attention to the caution that should be exercised in climate reconstructions, emphasizing the importance of considering the responsiveness of sample trees to directional changes in climate.

\section{ACKNOWLEDGMENTS}

For assistance with the fieldwork we thank Christine Shook and Sarah Johnson. Support was provided by the Office of Science, Biological and Environmental Research (BER) Program, US Department of Energy (DOE) as a part of the Program for Ecosystem Research.

\section{REFERENCE CITED}

Abrams, M. D., 1988a. Comparative plant and tissue water relations of three successional hardwood species in central Wisconsin. Tree Physiology 4:263-273.

Abrams, M. D., 1988b. Sources of variation in osmotic potentials with special reference to North American tree species. Forest Science 34:1030-1046.

Abrams, M. D., 1990. Adaptations and responses to drought in Quercus species of North America. Tree Physiology 7: 227-238.

Amato, I., 1988. Tapping tree-rings for the environmental tales they tell. Analytical Chemistry 60(11):1103A-1107A.

Barber, V. A., G. P. Juday, and B. P. Finney, 2000. Reduced growth of Alaskan white spruce in the twentieth century from temperature-induced drought stress. Nature 405:668-672.

Ciais, P. H., M. Reichstein, N. Viovy, A. Granier, J. Ogée, V. Allard, M. Aubinet, N. Buchmann, Chr. Bernhofer, A. Carrara, F. Chevallier, N. De Noblet, A. D. Friend, P. Friedlingstein, T. Grünwald, B. Heinesch, P. Keronen, A. Knohl, G. Krinner, D. Loustau, G. Manca, G. Matteucci1, F. Miglietta, J. M. Ourcival, D. Papale, K. Pilegaard, S. 
Rambal, G. Seufert, J. F. Soussana, M. J. Sanz, E. D. Schulze, T. Vesala, and R. Valentini, 2005. Europe-wide reduction in primary productivity caused by the heat and drought in 2003. Nature 437:529-533.

Cook, E. R., and R. L. Holmes, 1997. ARSTAN: chronology development. In The International Tree-Ring Data Bank Program Library, Version 2.1. User's manual, edited by H. D. Grissino- Mayer, R. L. Holmes, and H. C. Fritts, pp. 75-87. Laboratory of Tree-Ring Research. The University of Arizona, Tuscon, Arizona.

Cutter, B. E., and R. P. Guyette, 1993. Anatomical, chemical, and ecological factors affecting tree species choice in dendrochemistry studies. Journal of Environmental Quality 22:611-619.

D’Arrigo, R. D., R. K. Kaufmann, N. Davi, G. C. Jacoby, C. Laskowski, R. B. Myneni, and P. Cherubini, 2004. Thresholds for warming-induced growth decline at elevational tree line in the Yukon Territory, Canada. Global Biogeochemical Cycles 18:1-7.

Ericsson, T., L. Rytter, and E. Vapaavuori, 1996. Physiology of carbon allocation in trees. Biomass and Bioenergy 11: $115-127$.

Fay, P. A., D. M. Kaufman, J. B. Nippert, J. D. Carlisle, and C. W. Harper, 2008. Changes in grassland ecosystem function due to extreme rainfall events: Implications for responses to climate change. Global Change Biology 14: $1600-1608$.

Fritts, H. C., 2001. Tree-Ring and Climate. Blackburn Press, Caldwell, New Jersey, USA.

Grebe, G. M., T. J. Tschaplinski, and T. L. Shirshac, 1998. Water relations of several hardwood species in response to throughfall manipulation in an upland oak forest during a wet year. Tree Physiology 18:299-305.

Hanson, P. J., D. E. Todd, N. T. Edwards, and M. A. Huston, 1995. Field performance of the Walker Branch Throughfall Displacement Experiment. In EcosystemManipulation Experiments, edited by A. Jenkins, R. C. Ferrier, and C. Kirby, pp. 307-313. Ecosystems Research Report no. 20, Commission of the European Communities.

Hanson, P. J., D. E. Todd, M. A. Huston, C. T. Garten, Jr, and P. J. Mulholland, 1998. Description and field performance of the Walker Branch Throughfall Displacement Experiment: 1993-1996. ORNL TM-13586. Oak Ridge National Laboratory, Oak Ridge, Tennessee.

Hanson, P. J., D. E. Todd, and J. S. Amthor, 2001. A six year study of sapling and large-tree growth and mortality responses to natural and induced variability in precipitation and throughfall. Tree Physiology 21:345358.

Hanson, P. J., and J. F. Weltzin, 2000. Drought disturbance from climate change: Response of United States forests. Science of the Total Environment 262:205-220.

Hanson, P. J., D. E. Todd, D. C. West, N. T. Edwards, M. L. Tharp, and W. A. Simpson, Jr, 2003. Tree and sapling growth and mortality. In North American Temperate Deciduous Forest Responses to Changing Precipitation Regimes, edited by P. J. Hanson, and S. D. Wullschleger, pp. 255-273. Springer, New York.
Johnson, D. W., R. B. Susfalk, H. L. Gholz, and P. J. Hanson, 2000. Simulated effects of temperature and precipitation change in several forest ecosystems. Journal of Hydrology 235:183-204.

Johnson, D. W., P. J. Hanson, and D. E. Todd, 2002. The effects of throughfall manipulation on soil leaching in a deciduous forest. Journal of Environmental Quality 31:204-216.

Johnson, D. W., D. E. Todd, Jr, and P. J. Hanson, 2008. Effects of throughfall manipulation on soil nutrient status: Results of 12 years of sustained wet and dry treatments. Global Change Biology 14:1661-1675.

Kramer, P. J., 1980. Drought stress and the origin of adaptations. In Adaptation of Plants to Water and High Temperature Stress, edited by N. C. Turner, and P. J. Kramer, pp. 7-22. Wiley, New York.

Kubiske, M. E., and M. D. Abrams, 1994. Ecophysiological analysis of temperate woody species on contrasting sites during wet and dry years. Oecologia 98:303-312.

Martin, M., and M. Cheng, 2000. Detection of chromium aerosol using time-resolved laser-induced plasma spectroscopy. Applied Spectroscopy 54(9):1279-1285.

Martin, M. Z., S. D. Wullschleger, C. T. Garten, Jr, and A. V. Palumbo, 2003. Laser-induced breakdown spectroscopy for the environmental determination of total carbon and nitrogen in soils. Applied Optics 42:2072-2077.

Neilson, R. P., G. A. King, R. L. DeVelice, J. Lenihan, D. Marks, J. Dolph, W. Campbell, and G. Glick, 1989. Sensitivity of Ecological Landscapes to Global Climatic Change. US Environmental Protection Agency, EPA-600-389-073, NTIS-PB-90-120-072-AS, Washington DC, USA.

Pastor, J., and W. M. Post, 1988. Response of northern forest to $\mathrm{CO}_{2}$ induced climatic change: dependence on soil water and nitrogen availabilities. Nature 334:55-58.

Penninckx, V., S. Glineur, W. Gruber, J. Herbauts, and P. Meerts, 2001. Radial variations in wood mineral element concentrations: a comparison of beech and pedunculate oak from the Belgian Ardennes. Annals of Forest Science 58:253-260.

Piovesan, G., F. Biondi, A. Di Filippo, A. Alessandrini, and M. Maugeri, 2008. Drought-driven growth reduction in old beech (Fagus sylvatica L.) forests of the central Apennines, Italy. Global Change Biology 14:1-17.

Senior, C. A., R. G. Jones, J. A. Lowe, C. F. Durman, and D. Hudson, 2002. Predictions of extreme precipitation and sealevel rise under climate change. The Royal Society of London. Philosophical Transactions. Series A. Mathematical, Physical and Engineering Sciences 360(1796):1301-1311.

Solomon, S., D. Qin, M. Manning, Z. Chen, M. Marquis, K. B. Averyt, M. Tignor, and H. L. Miller, Editors, 2007. Climate Change 2007: The Physical Science Basis-Contribution of Working Group I to the Fourth Assessment Report of the Intergovernmental Panel on Climate Change (Cambridge Univ. Press, Cambridge, UK, New York, USA, 2007).

St George, S., P. M. Outridge, and E. Nielsen, 2006. Highresolution dendrochemical analysis of flood-affected oaks using laser ablation ICP-mass spectrometry. IAWA Journal 27:19-31.

Tschaplinski, T. J., G. M. Gebre, and T. L. Shirshac, 1998. Osmotic potential of several hardwood species as affected by manipulation of throughfall precipitation in an upland oak forest during a dry year. Tree Physiology 18:291-298. 
Wardell, J. F., and J. H. Hart, 1973. Radial gradients of elements in white oak wood. Wood Science 5(4):298-303.

Weltzin, J. F., M. E. Loik, S. Schwinning, D. G. Williams, P. A. Fay, B. M. Haddad, J. Harte, T. E. Huxman, A. K. Knapp, G. Lin, W. T. Pockman, M. R. Shaw, E. E. Small, M. D. Smith, S. D. Smith, D. T. Tissue, and J. C. Zak, 2003. Assessing the response of terrestrial ecosystems to potential changes in precipitation. Bioscience 53:941-952.

Wullschleger, S. D., F. C. Meinzer, and R. A. Vertessy, 1998. A review of whole-plant water use studies in trees. Tree Physiology 18:499-512.
Wullschleger, S. D., and P. J. Hanson, 2003. North American temperate deciduous forest. In Ecological Studies Series, Volume 166, edited by P. J. Hanson, and S. D. Wullschleger, pp. 363-377. Springer, New York, New York.

Received 27 August 2010; accepted 31 October 2011.

Supplementary Material is available at http://www.treeringsociety.org/TRBTRR/TRBTRR.htm 